\title{
Hereditary Recurrent Intrahepatic Cholestasis from Birth
}

\author{
Ø. AAGENÆS, C. B. VAN DER HAGEN, AND S. REFSUM \\ From the Department of Paediatrics, Rikshospitalet, the Institute of Medical Genetics; \\ and the Institutt for Generell og Eksperimentell Patologi, University of Oslo, Norway
}

Obstructive jaundice in the first months of life is a fairly frequent phenomenon. Approximately twothirds of these infants have atresia of the hepatic ducts, and about two-thirds of the remaining can be classified as 'neonatal hepatitis', 'giant cell hepatitis', or 'thick bile syndrome' (Craig and Landing, 1952; de Toni and Romano, 1962; Gellis, 1961). 'Thick bile syndrome' is defined as 'neonatal hepatitis syndrome' plus obstructive jaundice secondary to erythroblastosis fetalis (de Toni and Romano, 1962). These poorly defined syndromes have been studied extensively in the past 15 years, after the report in 1952 on the pathology of 'neonatal hepatitis' by Craig and Landing, who drew attention to the frequency of multinuclear giant cells in the liver in this syndrome. The confusion as to the entity of 'neonatal hepatitis' and its aetiology is well demonstrated by the responses from different authorities (Brent, 1962).

Earlier authors presumed a viral aetiology (Craig and Landing, 1952; Friis-Hansen, 1956; Gellis, 1961; Laplane et al., 1964, and others), homologous serum hepatitis virus, transmitted to the fetus transplacentally, being held responsible. The frequent finding of sibs with the disease was thought by Aterman (1963) and others to imply a lifelong viraemia in the mothers. Hartmann (1964) found a moderately increased serum bilirubin in the mother of three children with this syndrome, and thought that this pointed to a latent serum hepatitis in the mother.

Hsia et al. (1958) and Danks and Bodian (1963) analysed their material on 'neonatal hepatitis' from a genetic viewpoint, concluding that the frequency of affected sibs is not far from the supposed frequency, if the disease were caused by a recessive autosomal gene in homozygous form. Cassady, Morrison, and Cohen (1964) and Boon (1965) examined several sibs with the disease, and also favoured a genetic aetiology.
Neither aetiology has been proved, and typical of the confusion is that an authority such as Danks, from his work in 1963 favoured a genetic aetiology, but in 1965 (Danks, Campbell, and Connelly) preferred a virus aetiology for the majority of cases with 'neonatal hepatitis'.

Probably different diseases are hidden under the name 'neonatal hepatitis', and it is important therefore to try to extract the homogeneous components from this heterogeneous group.

\section{Material}

During the past few years, 16 cases of neonatal cholestasis from a small area in Southwest Norway have come to our attention (Table I). 4 of these (XI.2, XIII.3, XIII.4, and XIII.6), belonging to 3 sibships, were admitted to the Department of Paediatrics, Rikshospitalet. The remaining cases came to our attention through family questioning, with the exception of XIII.8, who was born in Rikshospitalet of an affected mother (XII.19).

The 16 patients belong to 7 sibships in the same

TABLE I

Chronological List of Patients with Recurrent Cholestasis from Birth

\begin{tabular}{|c|c|c|c|c|}
\hline $\begin{array}{l}\text { Pedigree } \\
\text { and sex }\end{array}$ & $\begin{array}{c}\text { Date of } \\
\text { Birth }\end{array}$ & $\begin{array}{c}\text { Cause of } \\
\text { Death }\end{array}$ & $\begin{array}{l}\text { Age at } \\
\text { Death }\end{array}$ & Living \\
\hline $\begin{array}{l}\text { XII.12(M) } \\
\text { XII.13(F) } \\
\text { XII.5(F) } \\
\text { XII.14(F) } \\
\text { XII.15(M) } \\
\text { XII.16(M) } \\
\text { XII.8(F) } \\
\text { XIII.7(M) } \\
\text { XII.9(M) } \\
\text { XI.2(F) } \\
\text { XII.19(F) } \\
\text { XI.4(M) } \\
\text { XIII.3(F) } \\
\text { XIII.4(F) } \\
\text { XIII.6(F) } \\
\text { XIII.8(F) }\end{array}$ & $\begin{array}{l}1933 \\
1934 \\
1934 \\
1935 \\
1938 \\
1940 \\
1941 \\
1942 \\
1943 \\
1943 \\
1944 \\
1951 \\
1961 \\
1962 \\
1966 \\
1966\end{array}$ & $\begin{array}{c}\text { Bleeding } \\
, " \\
, " \\
\text { Unknown } \\
\text { Bleeding? }\end{array}$ & $\begin{array}{l}3 \mathrm{wk} . \\
2 \mathrm{wk} . \\
3 \mathrm{wk} . \\
9 \mathrm{dy} . \\
6 \mathrm{mth} . \\
9 \mathrm{mth} . \\
5 \frac{1}{2} \mathrm{mth} .\end{array}$ & $\begin{array}{l}\mathbf{X} \\
\mathbf{X} \\
\mathbf{X} \\
\mathbf{X} \\
\mathbf{X} \\
\mathbf{X} \\
\mathbf{X} \\
\mathbf{X}\end{array}$ \\
\hline
\end{tabular}




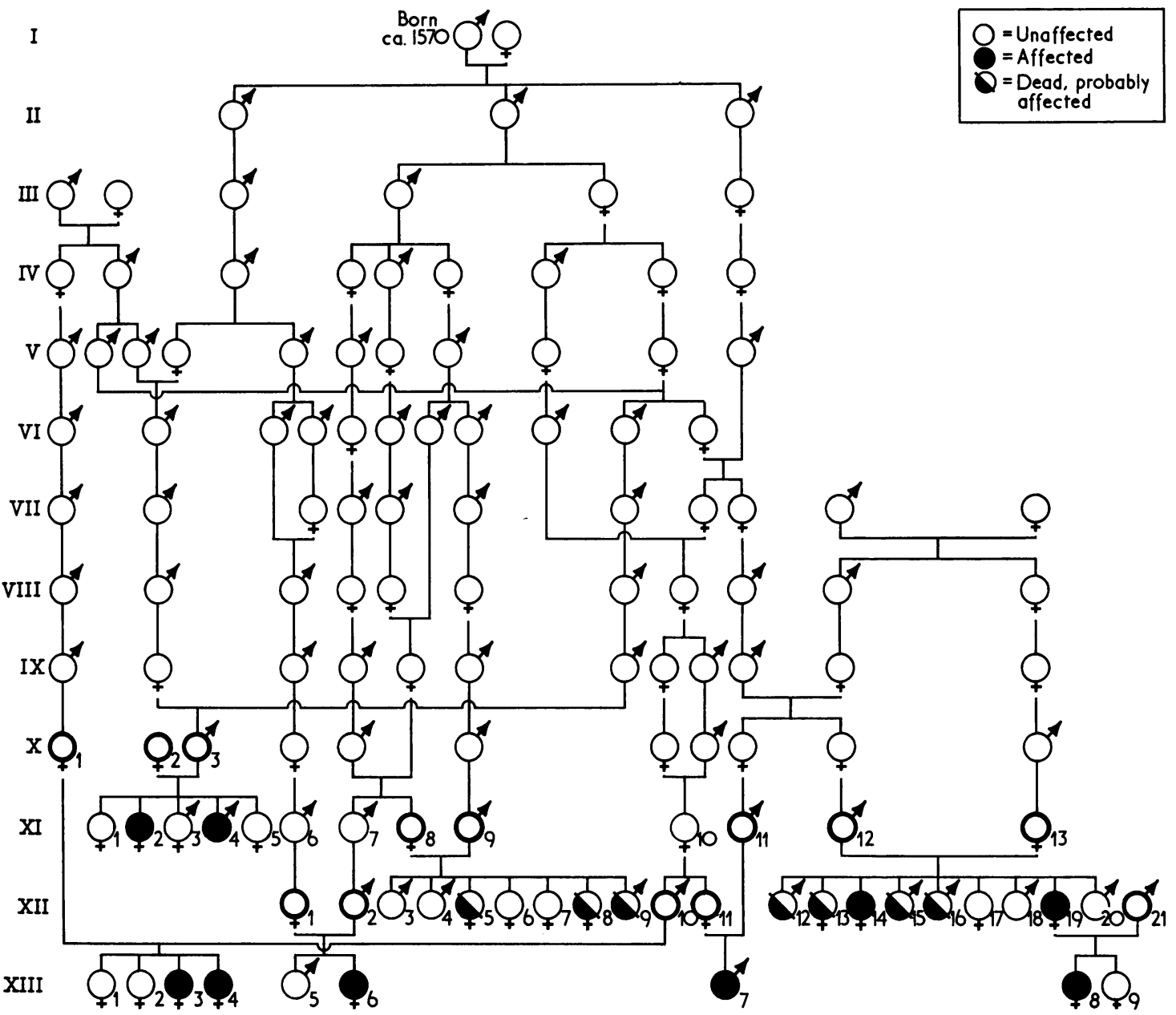

FIG. 1.-Pedigree of the family with congenital cholestasis. Parents of patients (heterozygotes?) are indicated by thick outlines to symbols.

family (Fig. 1). Of the 9 living patients, 8 have been examined by one of the authors (Ø.АA.). The ninth (XIII.7) has been examined in other hospitals, and blood specimens from him have been examined at the Department of Paediatrics.

In the 6 sibships with normal parents there are altogether 28 sibs, of whom 15, 6 boys and 9 girls, are affected. Excluding one proband in each sibship, and assuming recessive inheritance, the observed number of affected subjects, 9, does not differ significantly from the expected number, $5 \cdot 5$ $(0 \cdot 2<\mathrm{p}<0 \cdot 3)$.

In all sibships at least one parent could be traced back to common ancestors born about 1570, and in 3 sibships both parents were descendants of this sixteenth-century couple. In 2 other sibships the parents were consanguineous in other ways.
The seventh sibship should be given special consideration, since the mother is affected herself. Her husband comes from the same area, but consanguinity has still to be proved.

An estimation of the consanguinity rate in the total kindred has not been made, partly owing to the lack of knowledge of general consanguinity in the area.

It should be mentioned, however, that this part of Norway has been inhabited at least since A.D. 200300.

\section{Newborn Period}

All children were born after an uncomplicated pregnancy, except XIII.8, whose mother XII.19, developed a new phase of cholestasis during the last months of pregnancy. None of the other mothers has ever had jaundice or other symptoms of hepatitis. 
Delivery was uncomplicated in all cases, and where we know the birthweight, this was normal. All 16 children were jaundiced at birth or before 1 week of age. The stools were pale shortly after the termination of meconium, and urines were dark, but the children remained otherwise in good condition.

XIII.8 was observed by one of the authors (Ø.AA.) from birth. Cord blood was examined, with the following findings: bilirubin $6.8 \mathrm{mg}$./ $100 \mathrm{ml}$. (unconj. $3 \cdot 1 \mathrm{mg} . / 100 \mathrm{ml}$., conj. $3 \cdot 7 \mathrm{mg}$./ $100 \mathrm{ml}$.). Lipids: cholesterol $134 \mathrm{mg} . / 100 \mathrm{ml}$. (norm. $<100 \mathrm{mg} . / 100 \mathrm{ml}$.), phospholipids 172 (norm. $<150 \mathrm{mg} . / 100 \mathrm{ml}$.), triglycerides 146 mg. $/ 100 \mathrm{ml}$. (norm. $<60 \mathrm{mg} . / 100 \mathrm{ml}$.). The approximate normal values are taken from a Swedish source (Persson and Gentz, 1966) and an American source (Kaplan and Lee, 1965). Lipoprotein electrophoresis showed a considerable increase in $\beta$-lipoproteins, when compared with the pattern in cord blood from normal infants, where $\beta$-lipoprotein concentration is small. SGOT 91, SGPT 51 Karmen units. Protein electrophoresis was normal. The hyperbilirubinaemia, hyperlipaemia, and high transaminases all point to a prenatal liver disease.

Faecal fat at the age of 14 days was excreted at the rate of $6 \mathrm{~g}$./day (on an intake of about $10 \mathrm{~g}$./day).

In the 7 children who died in infancy (Table I) the diagnosis is based on the history of jaundice, dark urine, and pale stools from shortly after birth until death. Three of these (XII.16, XII.8, and XII.9) were examined in local hospitals where no important examinations were performed. The other 4 children were seen only by the parents and the local practitioners, but the facts were well documented.

Of 5 children born before 1939, when vitamin $\mathrm{K}$ was introduced, 4 died of haemorrhages in the first weeks of life and 1 is still alive.

Of the next 4 children who received one dose of vitamin $\mathrm{K}$ shortly after birth, 3 died between the ages of 5 and 9 months, at least 1 and probably 2 of haemorrhages.

The last 7 patients with the disease, most of whom have received vitamin $\mathrm{K}$ more consistently, are living; but without regular vitamin $\mathrm{K}$ treatment they have low prothrombin values and a bleeding tendency.

Fig. 2 shows the prothrombin index in patient XIII.3 (A.L.) at the age of 1 year, after a period without vitamin $\mathrm{K}$ supplement. After one injection of vitamin $\mathrm{K}$ the prothrombin index rose promptly to normal pointing to malabsorption as the most important cause of this bleeding tendency, rather than the liver disease per se.

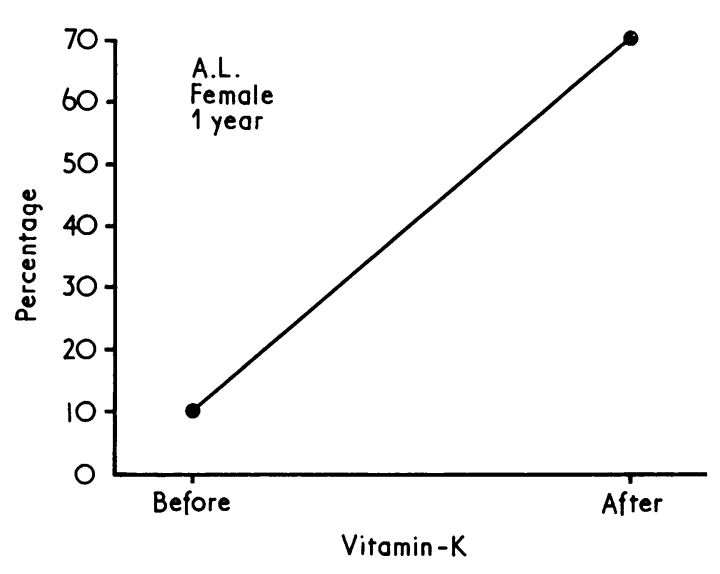

FIG. 2.-Prothrombin index inXIII.3, aged 1 year, before and the day after administration of $5 \mathrm{mg}$. vitamin $K$.

\section{Infancy and Early Childhood}

The children treated with vitamin $\mathrm{K}$ were usually referred to the Department of Paediatrics, with cholestatic jaundice in the second or third month of life. They were in good condition, and the admission diagnosis was usually atresia of the bile-ducts.

Differentiation between biliary atresia and cholestasis from other causes has not been possible by laboratory examinations, and, in recent years, exploratory laparotomy has been performed (XIII.3, XIII.4, XIII,6). The bile-ducts were then found to be normal, as was the liver macroscopically. Bile aspirated from the gall-bladder has been judged by the surgeon to be thick and inspissated in some instances, and in others to be normal.

The patients XII.14, XIII.7, XI2, XII.19, and XI.4, were not admitted to hospital in the first year of life. The symptoms in XII.14, XIII.7, and XI.2, would probably have resulted in an exploratory laparotomy in more recent years, but in XII.19 and XI.4 the jaundice was less pronounced and the stools were not completely acholic, and these 2 patients presumably would have always been treated conservatively.

The cholestasis persisted from about 1 year (XIII.7 and XI.4) to 5-6 years (XII.14, XI.2, XIII.3) in varying degree. Fig. 3 shows the serum bilirubin at different ages. In this figure and in the following figures the values at different ages were derived by examining various patients at various times. One patient (XIII.8) was examined as a newborn, 3 patients later in infancy (XIII.3, XIII.4, and XIII.6), 3 patients later in childhood (XI.2, XIII.3, and XIII.4), and 5 patients as adults (XII.14, XI.2, XIII.7, XII.19, and XI.4), 


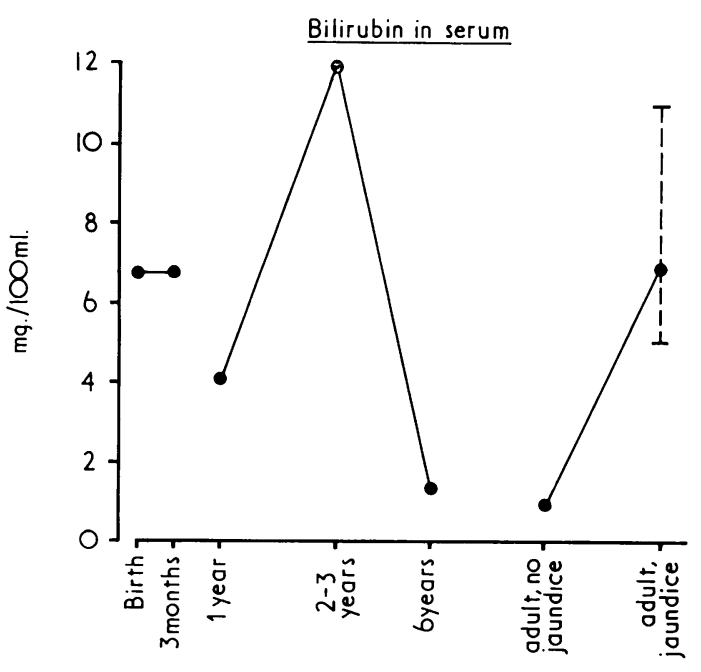

FIG. 3.-Course of serum bilirubin during life. (In this and the following figures, the diagrams show the characteristic course, rather than precise values from any single patient; see text.)

2 of these (XI.2 and XII.19) both in phases with cholestasis and in the intervals.

The increase in bilirubin was in both the conjugated and unconjugated components. In periods with severe hyperbilirubinaemia, usually $70-80 \%$ of the bilirubin was conjugated.

Patients over 6 months old complained of severe itching. In 2 adult patients, XI.2 and XII.19, and one child XIII.8, a bile acid examination was made during a period of cholestasis (Dr. Bremer, Institute

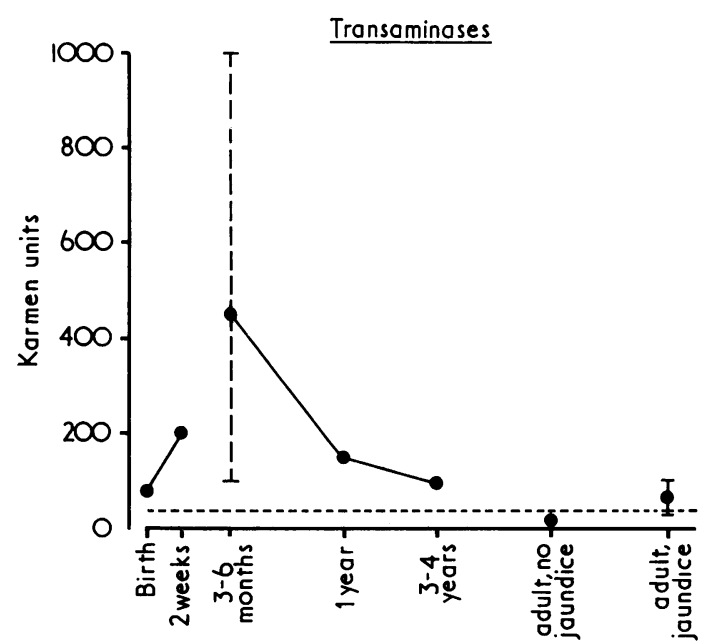

FIG. 4.-Transaminases (SGOT and SGPT) at different ages. Stippled line shows upper limit of normal. of Clinical Biochemistry, Rikshospitalet, Oslo). Total bile acids were found to be about $2-3 \mathrm{mg}$./ $100 \mathrm{ml}$. (normal $<0.23 \mathrm{mg}$. $/ 100 \mathrm{ml}$.).

The transaminases were always increased during periods of cholestasis (Fig. 4). The increase was highest in the first year of life, and both SGOT and SGPT were increased. The SGOT values were usually somewhat higher than the SGPT values. The highest SGOT value measured was 1400 Karmen units in XIII. 6 at 2 months of age. In cholestatic periods in later childhood, the transaminases were also increased, but not to the same degree, with values usually between 100 and 200 Karmen units.

Other liver function tests were usually normal. Thymol values were always normal. Total protein in serum tended to be normal, with a moderate decrease in albumin and increase in $\alpha_{2}$-globulin. Only one patient (XIII.7) had a severe hypoproteinaemia (total protein $4.0 \mathrm{mg} . / 100 \mathrm{ml}$. (alb. $2.7 \mathrm{mg}$., glob. $1.3 \mathrm{mg}$.)) at age 11 ; re-examination as an adult showed normal serum protein.

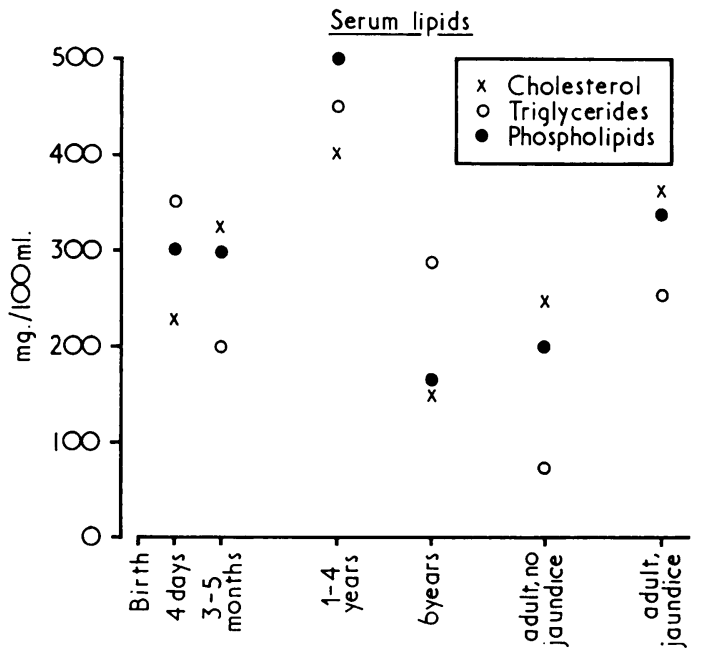

FIG. 5.-Serum lipids at different ages.

Serum lipids have been examined routinely, and in all periods of cholestasis, hyperlipaemia was found (Fig. 5). As in the newborn period, the triglycerides were most increased, but both cholesterol and phospholipids were usually also higher than normal. Lipoprotein electrophoresis showed increased pre- $\beta$ - and $\beta$-lipoproteins in the cholestatic periods.

Alkaline phosphatases were always increased in cholestatic periods, and most so in late infancy and early childhood, if the child had only received 


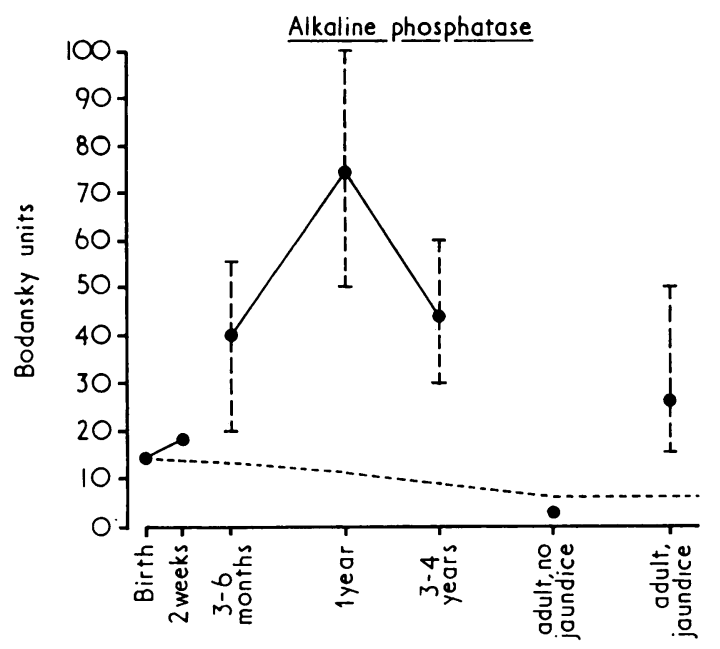

FIG. 6.-Alkaline phosphatases at different ages. Stippled line shows upper limit of normal.

the normal supplement of vitamin D (Fig. 6). These children also had biochemical and $x$-ray signs of rickets, the increase in alkaline phosphatases in these periods being thought to be due partly to liver phosphatases and partly to bone phosphatases.

Intravenous or oral cholecystography showed absent or only faint filling of the gall-bladder in the cholestatic periods, and the bromsulphalein retention tests in these periods showed a retention of $25-40 \%$ after 45 minutes. Galactose load gave a normal curve in all examined patients.

Serum copper was increased in the periods with cholestasis, as in patients with atresia of the bileducts.

Complications caused by malabsorption, other than haemorrhages and rickets, were the most important aspects of the disease in childhood. Malabsorption was present during all periods of cholestasis, as was repeatedly confirmed (Fig. 7). The faecal fat in the different age-groups was up

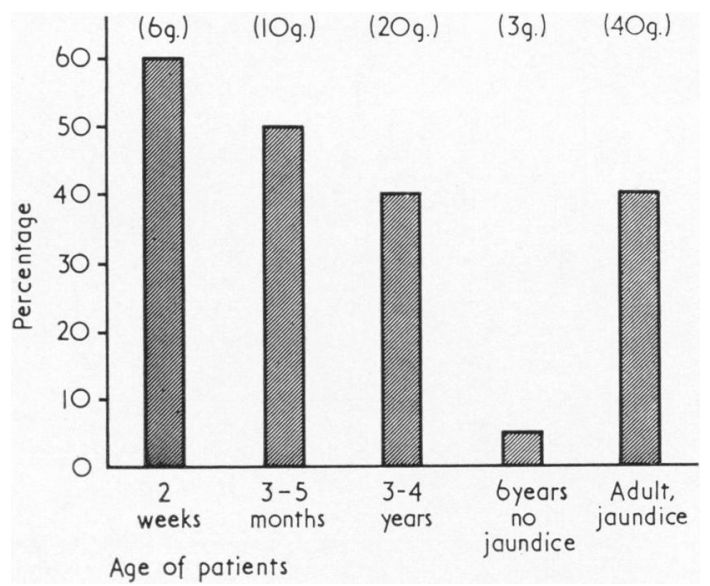

FIG. 7.-Faecal fat at different ages expressed as percentage fat in faeces, and as amount of fat excreted per day.

to about $30-50 \%$ of ingested fat. Faecal nitrogen excretion was always less than $1 \mathrm{~g}$./day.

The effects of malabsorption and the hyperbilirubinaemia are thought to be the causes of the conspicuous enamel defects and discoloration, in both the deciduous and the permanent teeth (Fig. 8).

In patients with severe malabsorption, growth retardation is pronounced. During the first year, body length tended to fall below the 2.5 centile, and at 4-5 years of age might be as low as $10 \mathrm{~cm}$. below the 2.5 centile. The growth curve of XIII. 3 (Fig. 9) shows how 'catch-up growth' starts when the cholestatic period stops (at 3-4 years of age in this case). The final height has been normal in the adult patients.

After some years of cholestasis, children develop a symptomless neuropathy with loss of deep tendon reflexes. Nerve conduction velocity was found to be low normal.

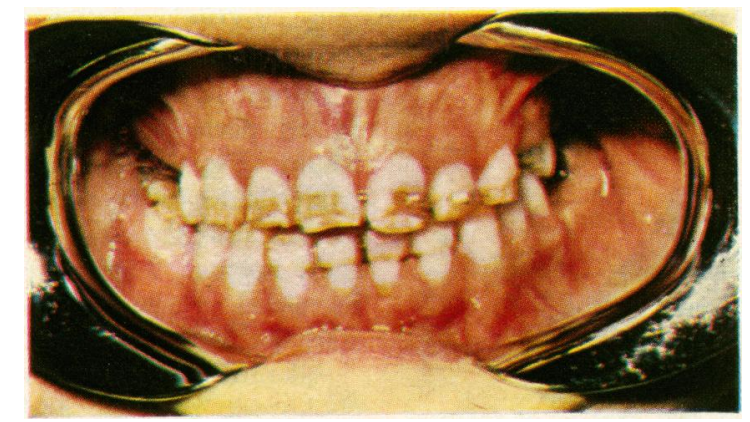

Fig. 8.-Enamel defects and discoloration of the teeth. 


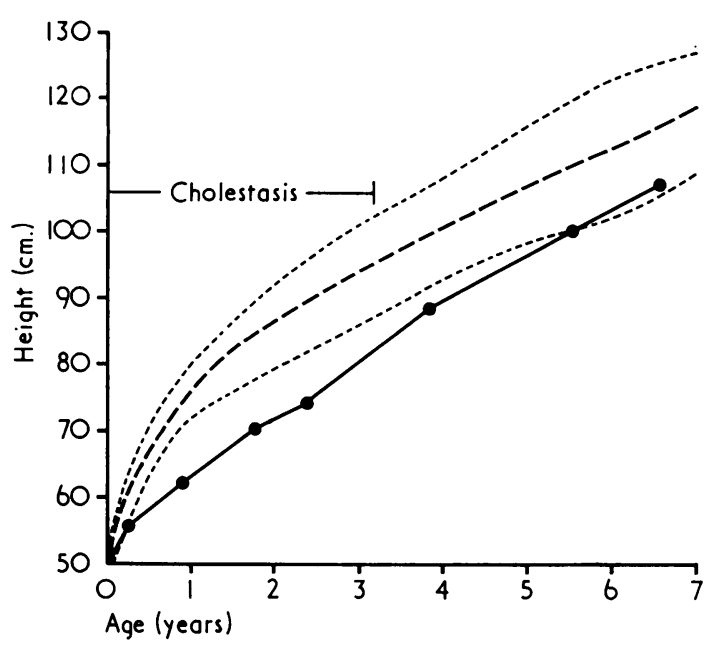

FIG. 9.-Growth curve of XIII.3, from birth to age $6 \frac{1}{2}$ years in relation to the curves for normal growth $(97 \cdot 5$, 50 , and $2 \cdot 5$ centiles).

\section{Later Childhood and Adulthood}

In the years of catch-up growth and prepuberty, all adult patients started to develop oedema, most pronounced in the legs (Fig. 10). At first it was present in the evenings, but absent in the mornings, but later was present throughout the day, though to a lesser extent after rest in bed. Oedema eventually became permanent both in cholestatic and noncholestatic periods, but in some patients the oedema seemed more pronounced in the periods without cholestasis. This complication has been the most severe problem for the adult patients. The oedema in the feet and distal part of the legs caused some difficulties in fitting shoes and boots, and the cosmetic problem might be even more serious, one of the female patients, XII.14, having undergone plastic surgery several times for 'elephantiasis' in the legs.

After the first long cholestatic period dating from birth, all patients have experienced one or more subsequent cholestatic periods. The highest number of the cholestatic periods is 5 (XII.14), while XII.19 has had only 2 new cholestatic periods during her 2 pregnancies, 16 and 17 years after the end of the first long cholestatic period. These recurrent cholestatic phases were usually of some months' duration, and in these periods the patients had jaundice, pale stools, dark urine, and itching. The degree of jaundice might be severe (Fig. 2), but slighter degrees of cholestasis, with only itching and no jaundice, have also been seen. The degree of malabsorption (Fig. 6), as well as the rise in alkaline phosphatases (Fig. 5), were also of the

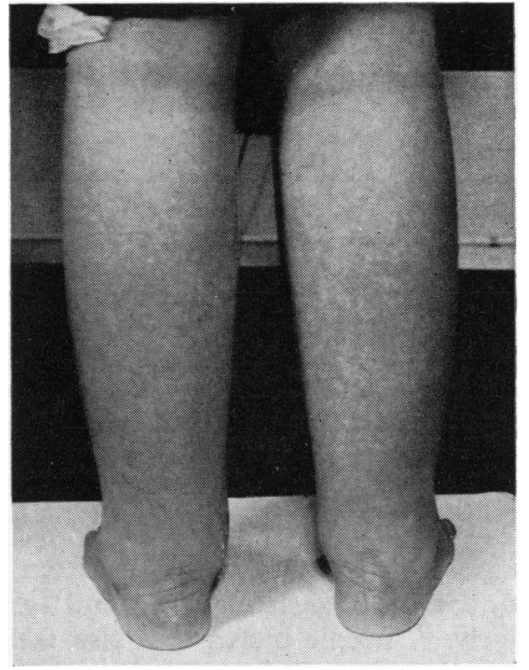

FIG. 10.-The oedematous legs of XII.14, at age 19 years.

same degree as in childhood, but the rise in transaminases was only slight (Fig. 3). The abnormalities in the blood lipids were the same as in the children (Fig. 4). However, the tendency to high $\alpha_{2}$-globulin and slightly decreased albumin were more pronounced than in the children.

Many of the recurrent cholestatic periods have started without known cause, but others have been provoked by operations (anaesthesia ?) or pregnancies. Infections have not provoked cholestasis, with one possible exception where measles induced itching but no jaundice.

In the non-icteric periods patients have no discernible signs of the disease, except the thick, oedematous legs and the enamel defects and discoloration of the teeth. Mental and motor development proceed normally. All the biochemical changes observed in the cholestatic periods have been repeatedly looked for in the non-icteric periods, and with few exceptions, such changes are then absent. The only exceptions to this are the following: (1) Alkaline phosphatases may be slightly increased years after the last cholestatic period. (2) Average serum bilirubin is slightly raised. The bilirubin value in 38 normal blood donors, compared with 5 patients in non-icteric periods, is shown in Table II.

In the cholestatic periods, the liver is enlarged, but in the intervals there is no clinical enlargement. No adult patient has developed symptoms of oesophageal varices, or other signs of portal hypertension. The oldest patient is at the moment 33 years old, and in good health. 
TABLE II

Average Total Serum Bilirubin in 5 Adult Patients in Phases Without Clinical Cholestasis, in 13 Parents, and in 38 Controls

\begin{tabular}{|c|c|}
\hline & $\begin{array}{l}\text { Serum } \\
\text { Total Bilirubin } \\
\text { (mg./100 ml.) }\end{array}$ \\
\hline $\begin{array}{l}\text { Patients in phases without clinical } \\
\text { cholestasis }(5) \quad . \\
\text { Parents of patients with cholestasis (13) } \\
\text { Control material (38) } . .\end{array}$ & $\begin{array}{l}1.12 \\
0.85 \\
0.54\end{array}$ \\
\hline
\end{tabular}

\section{Pathology}

A surgical liver biopsy was taken from XIII.3, 4 , and 6 , and at the ages of $5 \frac{1}{2}, 3 \frac{1}{2}$, and $3 \frac{1}{2}$ months, respectively. A needle biopsy was also taken from XIII.4 at the age of about 5 years. During an episode of icterus, needle biopsies were taken from 2 of the adults (XII.19 and XI.2).

Microscopically the liver biopsies from the children showed a preserved architecture. There was, however, partial collapse of some of the reticular fibres, with a slight increase in the amount of connective tissue in the periportal tracts and around the central veins. The parenchymal cells showed giant cell transformation, most pronounced in the first biopsy from XIII.4 at $3 \frac{1}{2}$ months (Fig. 11), considerably less in that taken at 5 years. Some of the parenchymal cells were arranged in a pseudo-tubular way, and many of the cells showed a considerable degree of degeneration.

There was slight bile-duct proliferation in the case of XIII.3, whereas in XIII.4 the bile-ducts were difficult to locate. In the needle biopsy from XIII.4 at 5 years no periportal tracts were found. Bile canaliculi were, in most instances, inconspicuous and difficult to find, though a few might be dilated and filled with a granular greenish-brown pigment, while in the needle biopsy from XIII.4 at 5 years they were dilated and filled with bile casts. In giant cells (as seen in XIII.3, 4, and 6 aged 5, 3, and 3 months), parenchymal cells, and Kupffer cells, there was an increased amount of a granular, green-brown pigment consisting of iron, bile, lipofuscin, and melanin (Fig. 12): in XIII.4 at 5 years no pigments other than bile were found.

In biopsies from the adults (XII.19 and XI.2, Fig. 13 and 14) the architecture was preserved, with a slight increase in the amount of connective tissue. Some of the parenchymal cells showed slight degeneration. A few multinucleated cells or giant cells were seen among the parenchymal cells. In some areas there was a pseudotubular arrangement of the parenchymal cells. Bile canaliculi were dilated and contained many bile casts.

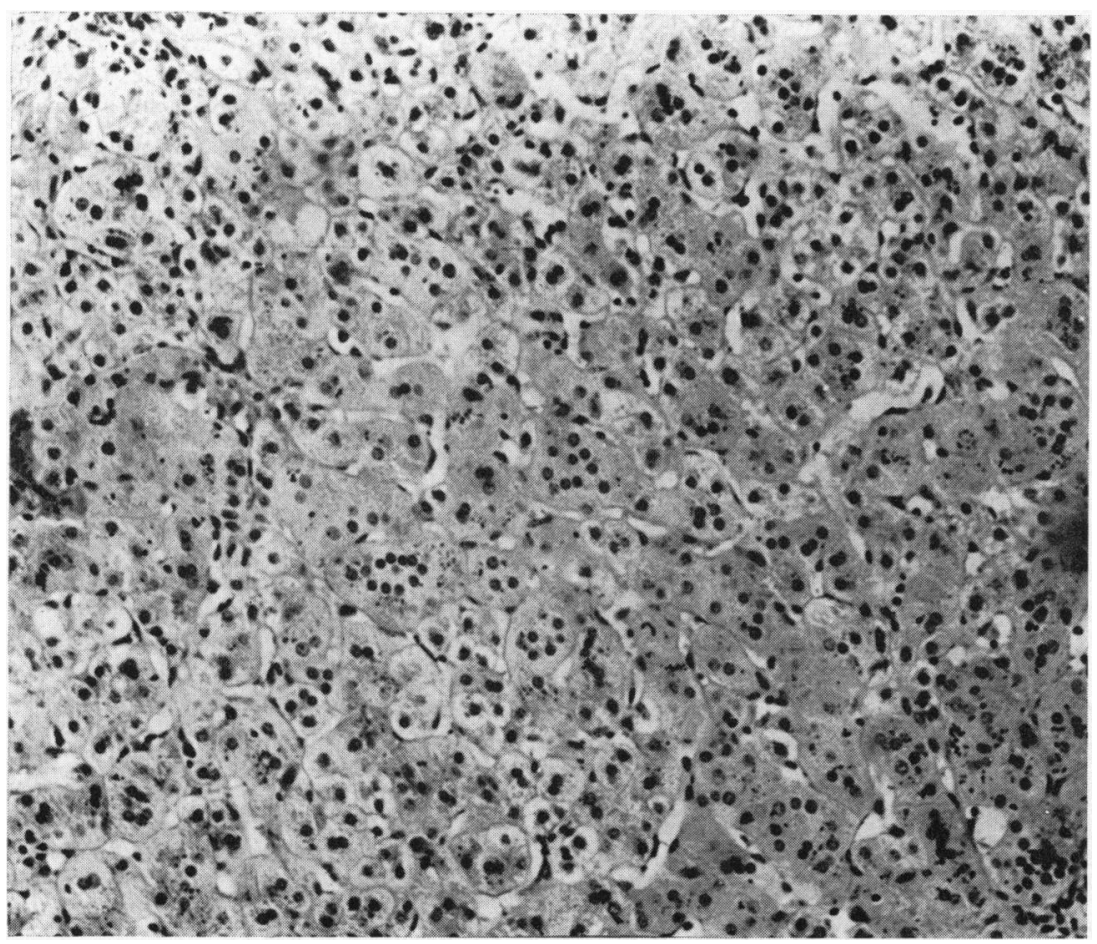

FIG. 11.-XIII.4. Liver biopsy at age $3 \frac{1}{2}$ months. Giant parenchymal cells. (Masson's trichrome. $\times 100$.) 


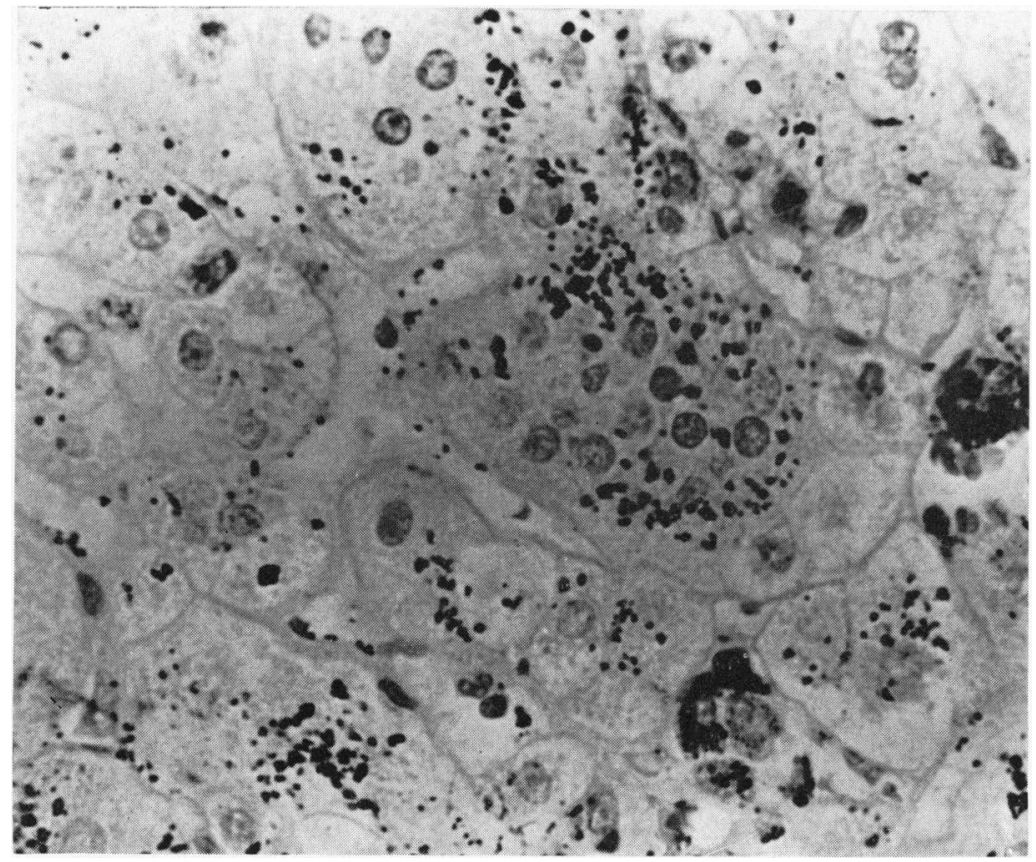

FIG. 12.-XIII.4. Liver biopsy at $3 \frac{1}{2}$ months. Increased amount of pigment in giant cells, parenchymal cells, and Kupffer cells. (Melanin stain. $\times 640$.)

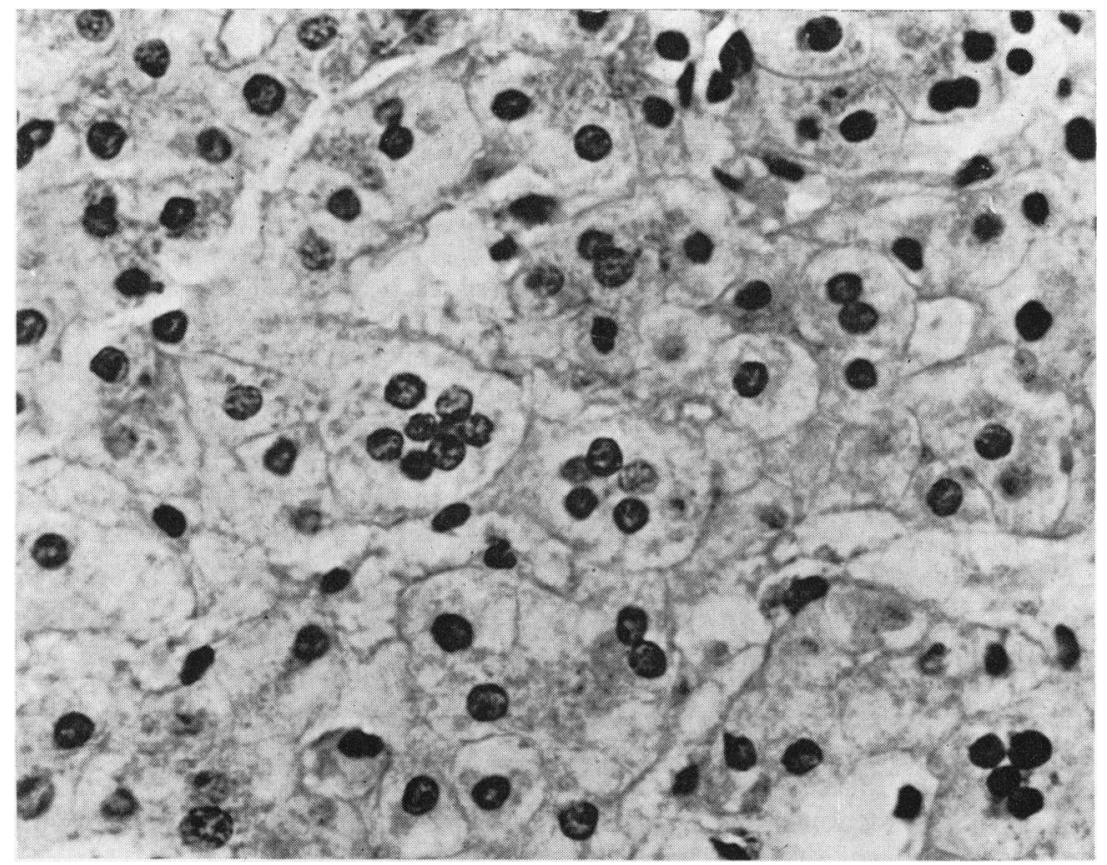

FIG. 13.-XII.19. Liver biopsy at 23 years. Multinucleated parenchymal cells and dilated canaliculi. (Masson's trichrome. $\times 580$.) 


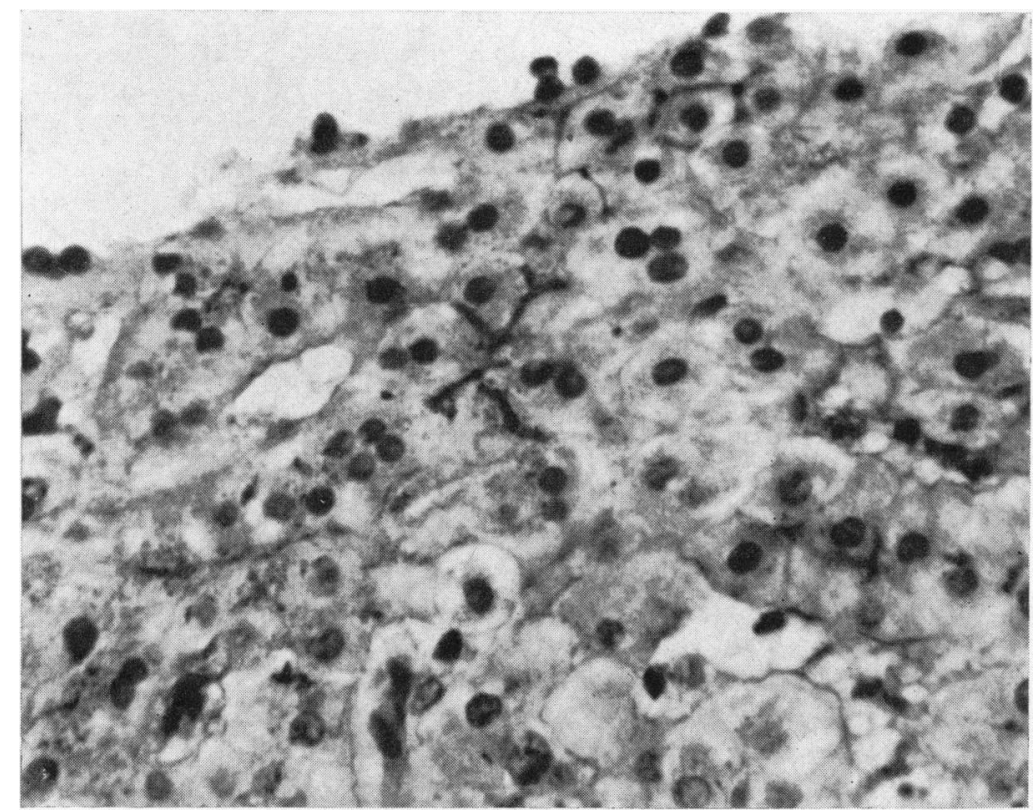

FIG. 14.-XI.2. Liver biopsy at 24 years. Dilated bile canaliculi and some multinucleated parenchymal cells. (Masson's trichrome. $\times 640$.

The parenchymal cells and the prominent Kupffer cells contained, especially around the central veins, increased amount of a yellow-brown pigment consisting of bile and without a trace of iron or melanin.

In summary, the histological picture in the infants was that of a giant-cell hepatitis or giant-cell transformation with intracytoplasmic pigment retention (Smetana, Edlow, and Glunz, 1965); whereas the adult cases showed an intracanalicular cholestasis with only a few multinucleated or giant cells. The biopsy from XIII.4, at the age of 5 years, showed a partial giant-cell transformation with intracanalicular cholestasis.

\section{Examination of Parents}

All 14 parents of the 7 sibships are living. As mentioned earlier, one of the mothers (XII.19) has the disease herself. The other 13 parents are all healthy. None of them has ever had jaundice, nor any other symptom of hepatitis.

Since the slightly raised serum bilirubin was the only abnormal finding in the non-cholestatic periods of affected subjects, the serum bilirubin was estimated in the parents (Table II). Total bilirubin was significantly increased in the parents compared with a group of 38 blood donors $(p<0.001)$. This increase might be a sign of heterozygosity. Further examination of the bilirubin patterns of the parents is in progress.

\section{Discussion}

The disease in our patients might be placed in one of the three syndromes: of 'neonatal hepatitis', 'recurrent, benign intrahepatic cholestasis', or 'hereditary hyperbilirubinaemia'.

In the neonatal period, the clinical picture fits completely into the 'neonatal hepatitis syndrome' of Craig and Landing (1952), Gellis, Craig, and Hsia (1954), and others. 'In the typical case of neonatal hepatitis, the infant appears normal at birth. In the first weeks of life, he is noted to be icteric, his stools pale, and his urine dark. The liver begins to enlarge. Usually the infant does not appear ill and continues to gain and thrive. In most cases there is no evidence of the passage of bile into the gastro-intestinal tract. The condition at this stage is indistinguishable from atresia of the bile ducts.' This clinical description of 'neonatal hepatitis' by Gellis (1961) is identical to that of our cases. The pathology in our cases is also identical with that described by Craig and Landing (1952). In the neonatal stage, therefore, our patients fit both clinically and pathologically into the 'neonatal hepatitis syndrome'.

The tendency to haemorrhages in the first weeks of life in 'neonatal hepatitis' is mentioned by Adams, Anderson, and Richdorf (1952) and Danks and Bodian (1963), but the importance of this 
tendency as a cause of death in the first weeks has not been stressed.

This may undoubtedly be attributed to the fact that the syndrome has been recognized mostly in the past 15 years, where vitamin $\mathrm{K}$ has been used either routinely at birth or at the slightest tendency to haemorrhages. Reports of the syndrome of 'neonatal hepatitis' before the time when vitamin $\mathrm{K}$ was introduced are lacking. It therefore seems reasonable to presume that the introduction of vitamin $\mathrm{K}$ has changed the prognosis in this disease, and that the high mortality in the newborn period before introduction of vitamin $\mathrm{K}$ ( 4 of 5 in the present group of patients) might explain why we find none with the disease in earlier generations.

Long-term follow-up studies of 'neonatal hepatitis' are still lacking. Hsia et al. (1958) found that about two-thirds of their cases seemed to be well at a follow-up 6 months to 12 years after recovery; the other third were dead or showed signs of cirrhosis. Danks and Bodian (1963) found that about one-third of their patients were likely to recover fully, but thought that the true prognosis might lie somewhere between Hsia's and their own estimations.

The duration of the first cholestatic period in our patients is longer than the average cited in the literature for cases of 'neonatal hepatitis'. Despite this, examination of our 5 adult patients at age 16-33 years shows none with signs of cirrhosis and the prognosis for the future seems good.

The course of the disease in later childhood and adulthood in these patients also places the disease close to the syndrome of 'benign, recurrent intrahepatic cholestasis', first described by Summerskill and Walshe (1959), later also by Tygstrup (1960), Summerskill (1965), and others. About 20 patients have been reported with benign recurrent cholestasis, usually starting in childhood and lasting for a few months. Biochemical findings in the periods of cholestasis are similar to those in our patients, though hyperlipaemia is less consistent.

Our patients differ from the patients with 'benign, recurrent intrahepatic cholestasis' in the following: (a) they have their first cholestatic period at birth; (b) they develop oedema in prepuberty; (c) liver biopsies show giant cells in addition to the cholestasis; $(d)$ the disease is clearly genetic; and (e) the patients always have hyperlipaemia in the cholestatic periods.

The third group of syndromes, with which our disease might naturally be grouped, is that of the hereditary hyperbilirubinaemias. As the bilirubin in our patients is primarily of the conjugated form, they do not fit into the Crigler-Najjar syndrome, Arias syndrome, or Gilbert's syndrome. The clinical and histological characteristics also differ considerably from the syndromes with hereditary conjugated hyperbilirubinaemia, DubinJohnson syndrome and Rotor syndrome. In these, there is an excretion defect of bilirubin, while our patients have an excretion defect of bile acids and lipids, as well as of bilirubin.

In recent years, 6 sibships with intrahepatic cholestasis in infancy and increased conjugated bilirubin in serum have been published (Clayton et al., 1965; Gray and Saunders, 1966; Juberg et al., 1966). Clayton et al. published 6 cases of intrahepatic cholestasis in 4 sibships. All 8 parents could be traced to a common ancestral couple, suggesting autosomal recessive inheritance. The clinical characteristics were early onset of loose, malodorous stools, and 'attacks' of jaundice starting from one to eight months after the onset of gastrointestinal symptoms. 4 of the 6 children died of cirrhosis before 8 years of age. Serum cholesterol was in the low normal range.

Juberg et al. (1966) reported 4 sibs with intrahepatic cholestatis from infancy, but not from the neonatal period. The first symptom was pruritus; hyperbilirubinaemia started later and was most often slight. There was retardation of growth and mild mental retardation. Progressive liver fibrosis developed.

Gray and Saunders (1966) reported two sibs with obstructive jaundice in the neonatal period, who developed severe fibrosis and died when they were only a few years old.

In none of these sibships, was the pattern of disease similar to that in our cases. Bile acid stasis seemed to be the primary defect in Clayton's and Juberg's cases, and as the hyperbilirubinaemia was slight, it may well have been secondary to bile acid stasis. Nor were their cases hyperlipaemic.

Thus we must therefore recognize three different types of hereditary excretion defects from the liver cells. (1) Dubin-Johnson and Rotor syndrome, with excretion defect of bilirubin; (2) Juberg's and Clayton's cases,with a probable excretion defect of bile acids; and (3) our syndrome, with an excretion defect of bilirubin, bile acids, and lipids.

Aetiology. As mentioned earlier two possible aetiologies for 'neonatal, cholestatic hepatitis' have been proposed: infection, and inborn error of metabolism. Recently, Perrin, Guimbretière, and Harousseau (1966) have proposed that the aetiology might be a feto-maternal incompatibility with iso-antibodies against liver tissue, but their experimental data for this theory seem inconclusive. 
The occurrence of 16 well-defined cases of this rare disease in 7 sibships of the same kindred is indicative of a genetic aetiology, and the segregation is wholly consistent with an autosomal recessive mode of inheritance. All parents except one are unaffected by the disease, and it is reasonable to assume that they are heterozygotes for the gene.

The one affected subject, who has conceived, produced one affected and one unaffected child; this would be expected assuming she is homozygous and her husband heterozygous for the gene.

It might be argued that in an isolated community such as this, the chances of finding consanguinity over 10 to 13 generations are bound to be high. On the other hand, our cases do not all live in the same area today, nor were all disclosed through family questioning. Moreover, the area has been inhabited for almost 2000 years, so that it is hardly likely that all or nearly all of the inhabitants are descended from one ancient pair of settlers.

Pathogenesis and pathology. The recessive autosomal inheritance is suggestive of a biochemical defect, but no specific defect has been detected. A possible biochemical defect might cause a general metabolic block, a localized excretion defect in the liver, or a structural change of the liver architecture.

Smetana et al. (1965) have suggested that as the giant cells fill the entire space between the sinusoids, no normal bile canaliculi can be formed between the parenchymal cells. Both the conjugated bile and other pigments normally excreted with the bile are therefore retained intracytoplasmically in the parenchymal cells. Due to the increasing amount of pigments within the parenchymal cells, these will eventually degenerate and die, with liberation of the pigments to macrophages and Kupffer cells. If the giant cell transformation is total, degenerated parenchymal cells will not be replaced; the structure will collapse and be replaced by reticular fibres and fibroblasts. Such a situation will usually lead to death within the first 6 to 8 months. With a partial giant cell transformation, the degenerated parenchymal cells may be replaced by normal parenchymal cells which have the ability to form normal bile canaliculi. Provided there are no other obstructions in the biliary tree (no biliary atresia), both the bile and the other pigments may be excreted. The liver may therefore return to nearly normal structure; there may be some residual collapse of the structure with an increased amount of reticular and fibrocytic fibres, but no liver cirrhosis.

The replacement of giant cells by normal paren- chymal cells seems, in our cases, to be a rather slow and incomplete process, inasmuch as we still find some giant cells in the adult livers. Though bile canaliculi have been formed, there still persists a recurrent defect in the bile excretion, with intracanalicular and intracellular bile retention as the result.

The cause of this defect in the bile excretion, which seems to affect all components of the bile, is unknown.

It is impossible to differentiate histologically the giant cell transformation in the livers in our patients from that found in other liver disorders in the neonatal period. The differentiation from other intrahepatic cholestatic conditions in adult livers (Summerskill, 1965) is also difficult, though giant cells in the liver in the Summerskill type of cholestasis (Williams et al., 1964) have not been reported.

\section{Summary}

Sixteen cases of neonatal cholestasis, all related, with consanguinity in 6 of 7 parental couples are reported. The children had an obstructive type of jaundice from the first week of life.

The jaundice lasted from about 1 to 6 years, and in this period the patients complained of severe itching. Other symptoms, such as bleeding tendency, rickets, anaemia, and growth retardation were ascribed to malabsorption.

Seven children died in infancy, at least 5 as a result of haemorrhages, but no death from haemorrhage has occurred since vitamin $\mathrm{K}$ has been regularly used.

Laboratory examinations showed hyperbilirubinaemia (conjugated bilirubin), increased transaminases and alkaline phosphatases, hyperlipaemia, and increase in pre- $\beta$ and $\beta$-lipoproteins, slight decrease in albumin, and increase in $\alpha_{2}$ globulin.

After the end of the cholestatic period, the children started to regain normal stature, and adult height was normal.

From prepuberty patients tended to develop oedema of the legs, for no known reason.

One or more further periods of cholestasis have recurred in all adult patients.

Liver histology showed 'giant cell hepatitis', but this did not progress to fibrosis.

The parents showed a slight but significant increase in serum bilirubin, possible evidence of heterozygosity.

The term 'hereditary, recurrent, intrahepatic cholestasis from birth' is proposed for this new inborn error of metabolism. 


\section{Hereditary Recurrent Intrahepatic Cholestasis from Birth}

We are grateful to Mr. Ola Knutrud who performed the laparotomies, to Drs. Helge Sigstad and Egil Gjone for examination of the adult patients and for the needle biopsies, to Dr. Georg Omland for the ambulatory specimen taken, to Drs. Jørgen Fog and Arne Bakken for the bilirubin examinations and for many fruitful discussions, and to Dr. Per Seland for supporting us with his knowledge of local genealogy.

This study was supported by a grant from Nordisk Insulinfond.

\section{REFERENCES}

Adams, F. H., Anderson, R. C., and Richdorf, L. F. (1952). Four siblings with hepatic disease leading to cirrhosis. Amer. 7 . Dis. Child., 84, 168.

Aterman, K. (1963). Neonatale hepatitis and its relation to viral hepatitis of mother. ibid., 105, 395.

Boon, J. M. (1965). Neonatale hepatitis of familiale neonatale stuwingsicterus. Maandschr. Kindergeneesk., 33, 465.

Brent, R. L. (1962). Persistent jaundice in infancy. F. Pediat., 61, 111.

Cassady, G., Morrison, A. B., and Cohen, M. M. (1964). Familial 'Giant-cell hepatitis' in infancy. Amer. F. Dis. Child., 107, 456.

Clayton, R. J., Iber, F. L., Ruebner, B. H., and McKusick, V. A (1965). Byler's disease: fatal familial intrahepatic cholestasis in an Amish kindred. $\mathcal{F}$. Pediat., 67, 1025.

Craig, J. M., and Landing, B. H. (1952). Form of hepatitis in neonatal period simulating biliary atresia. Arch. Path., 54, 321.

Danks, D., and Bodian, M. (1963). A genetic study of neonatal obstructive jaundice. Arch. Dis. Childh., 38, 378.

- Campbell, P. E., and Connelly, J. F. (1965). An aetiological study of neonatal jaundice in a children's hospital. Aust. paediat. F., 1, 193.

Friis-Hansen, B. (1956). Neonatal hepatitis with osteomalacia. Acta paediat. (Uppsala), 45, 376.
Gellis, S. S. (1961). Current problems in liver disease in infancy and childhood. Neonatal hepatitis. Progr. Liver Dis., 1, 61.

- Craig, J. M., and Hsia, D. Y. -Y. (1954). Prolonged obstructive jaundice in infancy. IV. Neonatal hepatitis. Amer. F. Dis. Child., 88, 285.

Gray, O. P., and Saunders, R. A. (1966). Familial intrahepatic cholestatic jaundice in infancy. Arch. Dis. Childh., 41, 320.

Hartmann, W. (1964). Zur Kenntnis der Neugeborenenhepatitis (Riesenzellenhepatitis). Z. Kinderheilk., 89, 146.

Hsia, D. Y. -Y., Boggs, J. D., Driscoll, S. G., and Gellis, S. S. (1958). Prolonged obstructive jaundice in infancy. V. The genetic components in neonatal hepatitis. Amer. F. Dis. Child. $95,485$.

Juberg, R. C., Holland-Moritz, R. M., Henley, K. S., and Gonzalez, C. F. (1966). Familial intrahepatic cholestasis with mental and growth retardation. Pediatrics, 38, 819 .

Kaplan, A., and Lee, V. F. (1965). Serum lipid levels in infants and mothers at parturition. Clin. chim. Acta, 12, 258.

Laplane, R., Graveleau, D., Lods, C., and Noum, I. (1964). Les hépatites néonatales familiales. Pédiatrie, 19, 217.

Perrin, D., Guimbretière, J., and Harousseau, H. (1966). Une nouvelle forme d'incompatibilité foeto-maternelle: l'hépatite néo-natale familiale. Presse méd., 74, 1307.

Persson, B., and Gentz, J. (1966). The pattern of blood lipids, glycerol and ketone bodies during the neonatal period, infancy and childhood. Acta paediat. (Uppsala), 55, 353.

Smetana, H. F., Edlow, J. B., and Glunz, P. R. (1965). Neonatal jaundice. Arch. Path., 80, 553.

Summerskill, W. H. J. (1965). The syndrome of benign recurrent cholestasis. Amer. F. Med., 38, 298.

- , and Walshe, J. M. (1959). Benign recurrent intrahepatic 'obstructive' jaundice. Lancet, 2, 686

de Toni G., and Romano, C. (1962). La sindroma da bile spessa nel primo trimestre di vita. Minerva pediat., 14, 1429.

Tygstrup, N. (1960). Intermittent possibly familial intrahepatic cholestatic jaundice. Lancet, 1, 1171.

Williams, R., Cartter, M. A., Sherlock, S., Scheuer, P. J., and Hill, K. R. (1964). Idiopathic recurrent cholestasis: a study of the functional and pathological lesions in four cases. Quart. $\mathcal{F}$. Med., n.s 33, 387 . 